BULLETIN OF THE

AMERICAN MATHEMATICAL SOCIETY

Volume 77, Number 6, November 1971

\title{
ERRATUM, VOLUME 76
}

M. Hochster and John A. Eagon, A class of perfect determinantal ideals, pp. 1026-1029.

The fourth line in the statement of Theorem 1, p. 1026: The sentence "Let $n$ be an integer, $0 \leqq n \leqq s$ " should read "Let $n$ be an integer such that $n=s_{t}$ or $n=s_{t}+1$ for some $t, 0 \leqq t \leqq m . "$

The third line in the statement of Theorem 2,p. 1027: The sentence, "If $n=s_{t}, 1 \leqq t \leqq m$, then $I_{H, n}$ is prime," should read, "If $n=s_{t}$, $0 \leqq t \leqq m$, then $I_{H, n}$ is prime."

\section{ERRATA, VOLUME 77}

The Summer Meeting in Laramie, p. 53.

The amended form of Article III, Section 1, should read:

There shall be nine publications committees, which shall consist of eight editorial committees specified in Section 2 of this article and the Committee on Printing and Publishing specified in Section 3 of this article, and one Communication Committee.

In the amended version of Article IV, Section 1, the third line should read:

"publications committees" instead of "publications committee."

Carl Faith. A correspondence theorem for projective modules and the structure of simple noetherian rings, pp. 338-342.

The following reference should have been added to the list of references

1967. R. Hart, Simple rings with uniform right ideals, J. London Math. Soc. 42 (1967), 614-617. MR 36 \#1477.

\section{ADDENDUM TO FINITE DIMENSIONAL $H$-SPACES}

\section{BY MORTON CURTIS}

Concerning remark (e), pp. 8-9, Curjel has informed me that H. Hosli has found a gap in Curjel's sketch of the proof of the assertion on the primitive generation of $H^{*}(X ; Q)$. 